\title{
Comparison of Efficacy of First Haemodialysis Session for Correction of Metabolic Disturbances in Acute Kidney Injury and Chronic Kidney Disease in Children
}

\section{Shubham Verma, Abhishek Abhinay, Om Prakash Mishra, Ankur Singh and Rajniti Prasad}

Division of Paediatric Nephrology, Department of Paediatrics, Institute of Medical Sciences, Banaras Hindu University, Varanasi, India

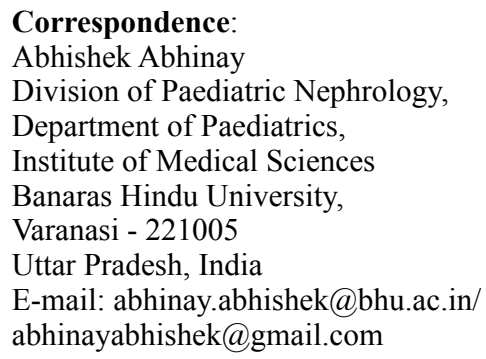

DOI: $10.3126 /$ jnps.v41i1.30825

Submitted on: $2020-05-11$

Accepted on: 2020-06-19

\section{Acknowledgements: None}

Funding: Nil

Conflict of Interest: None declared

Permission from IRB: Yes

To cite this article: Verma $S$, Abhinay A, Mishra OP, Singh A, Prasad R. Comparison of Efficacy of First Hemodialysis Session for Correction of Metabolic Disturbances in Acute Kidney Injury and Chronic Kidney Disease in Children. J Nepal Paediatr Soc. 2021;41(1):35-41.

\begin{abstract}
Introduction: Acute kidney injury and chronic kidney disease present with various complications like electrolyte disturbances, metabolic acidosis and fluid overload in children. The objective of the study was to compare the efficacy of the first session of haemodialysis in children with acute kidney injury stage 3 and chronic kidney disease G5 treated by dialysis for immediate recovery of renal functions in terms of reduction in the level of azotemia, correction of fluid and electrolyte imbalances, metabolic acidosis, and improvement in clinical status.
\end{abstract}

Methods: This was a cross-sectional comparative observational study conducted on 13 patients of acute kidney injury stage 3 and 46 patients with chronic kidney disease G5, who required haemodialysis. Their clinical assessment, fluid status, renal function tests, electrolyte, bicarbonate were done at admission and completion of the first session of heamodialysis.

Results: The age group of children was six to 16 years (median 11.4 years). There were six males (46\%) and seven females (54\%) in the acute kidney injury group and $29(63 \%)$ males and $17(37 \%)$ females in chronic kidney disease G5 groups. Sepsis (31\%) and glomerulonephritis (31\%) were common etiologies detected for acute kidney injury while in chronic kidney disease G5, congenital anomalies of the kidney and the urinary tract were the commonest $(50 \%)$. There were significant reductions in the levels of serum urea and creatinine and a rise in blood $\mathrm{pH}$, bicarbonate level, and base excess following the first session of haemodialysis in comparison to pre-dialysis values in both AKI and CKD.

Conclusions: The study demonstrated improvement in the clinical parameters and biochemical parameters equally after the first dialysis sessions in both groups. This is one of the effective renal replacement therapy and should be instituted wherever indicated to improve the immediate outcome of the patients.

Keywords: Azotemia; Chronic Kidney disease; Hemodialysis; Renal replacement therapy

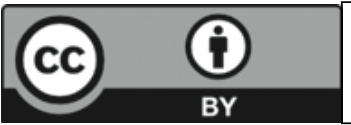

This work is licensed under creative common attribution 3.0 license 


\section{INTRODUCTION}

Acute Kidney Injury (AKI) and Chronic Kidney Disease Grade 5 (CKD G5) are common problems seen in paediatric kidney disease patients. AKI and CKD G5 have a different spectrum of clinical manifestations. AKI has high mortality with almost complete recovery of renal functions in survivors, but in CKD G5 there are various co-morbidities with residual disease and higher mortality. ${ }^{1-3}$ Various protocols are there for the management of AKI and CKD G5.,5 Dialysis is the treatment of choice for managing acute complications in both non-resolving AKI and CKD G5 for decreasing mortality and quick recovery of biochemical parameters deranged due to kidney failure. ${ }^{6,7}$

The incidence of AKI in the general ward is around $5 \%$, which increases up to $25 \%$ in PICU admission. ${ }^{1}$ Recently some authors have also reported incidence of AKI ranging between $23.7 \%$ to $26.9 \%$ in PICU admissions. ${ }^{8}{ }^{8}$ The etiologies of AKI previously reported from our centre were haemolytic uremic syndrome, acute tubular necrosis, and acute glomerulonephritis, ${ }^{10}$ while other authors ${ }^{6}$ found renal cause the most common followed by sepsis, drug intoxication, and obstructive uropathy. The prevalence of paediatric CKD ranged between 15 - 74.7 cases per million children. ${ }^{11}$ Chiou et al. ${ }^{12}$ reported stage-wise distribution of paediatric CKD as stage 1 (41.6\%), stage $2(41.9 \%)$, stage $3(13.4 \%)$, and stage 4 (3.1\%) from Taiwan Paediatric Renal Collaborative Registry. Among etiologies of CKD and CKD G5, Harambat et al. ${ }^{2}$ compiled data from various renal registries across the world and reported that congenital anomalies of the kidney and urinary tract (CAKUT) is the commonest cause of CKD (48 - 59\%) and CKD G5 (34 - 43\%) followed by glomerulonephritis $(5-14 \%$ and $15-29 \%$, respectively) in children below 20 years of age.

There are different modalities of dialysis therapy such as peritoneal dialysis, haemodialysis, haemodiafiltration, and continuous renal replacement therapy (CRRT). Each modality has its benefits and limitations. ${ }^{13,14}$ The haemodialysis and CRRT need vascular access, anticoagulation, moderate to high cost, ultrafiltration control, and rapid recovery. Peritoneal dialysis is easy to perform but is slow in recovery, no need for anticoagulation, and vascular access and often the only modality of therapy available for patients of AKI stage 3D and CKD G5D in resource-poor settings in developing countries..$^{10}$ Basu et al. ${ }^{15}$ observed no differences in mortality and renal function recovery between peritoneal dialysis and haemodialysis in children with AKI. Mortality and renal function recovery were based upon the etiology of AKI and associated co-morbidities. Delay in diagnosis and referral and associated complications are the factors responsible for the mortality of as high as $46 \%$ in patients of AKI. ${ }^{1}$ Peritoneal dialysis and haemodialysis / haemodia-filtration are modes of dialysis in children with CKD G5D. As such ours being a tertiary care referral hospital, we get both patients of AKI and CKD G5D and mostly with complications. As such, there is an acute change in fluid and electrolyte and metabolic disturbances in AKI which is presumed to have occurred in the previous 48 hours to seven days. By contrast, patients of CKD G5D have a prolonged period of azotemia usually of more than three months duration and adjusted with the morbidity, and decompensation occurs if not on regular maintenance dialysis.

Therefore, the objective of this study was to find out whether there is any difference in the comparative efficacy of haemodialysis in children with AKI stage 3D and CKD G5D for immediate recovery of renal function in terms of reduction in the level of azotemia, correction of overload, electrolyte imbalances, metabolic acidosis and improvement in clinical condition.

\section{METHODS}

This was a hospital-based cross-sectional comparative observational study conducted at a tertiary care centre of a teaching hospital in India from November 2016 to March 2019. Thirteen patients of AKI stage 3 and 46 patients of CKD G5D, who satisfied the inclusion criteria and had indications of haemodialysis as a supportive measure were included. The nomenclature of study subjects was adopted as per the recent Kidney Disease: Improving Global Outcomes (KDIGO) Consensus Conference. ${ }^{16}$ The inclusion criteria were patients with azotemic manifestations like nausea, vomiting, mental confusion, severe weakness, seizures / coma, acidotic breathing, persistent oliguria (urine output $<0.3 \mathrm{ml} / \mathrm{kg} / \mathrm{h}$ for $\geq$ 
Table 1. Clinical features at presentation in children with AKI stage 3 and CKD G5D

\begin{tabular}{|c|c|c|c|}
\hline Symptoms & $\begin{array}{c}\text { AKI stage } \\
3 \\
(n=13)\end{array}$ & $\begin{array}{c}\text { CKD G5D } \\
(n=46)\end{array}$ & $\begin{array}{c}\text { p- } \\
\text { value } \\
*\end{array}$ \\
\hline Oliguria & $8(61.5 \%)$ & $33(71.7 \%)$ & 0.378 \\
\hline Respiratory distress & $8(61.5 \%)$ & $23(50.0 \%)$ & 0.567 \\
\hline Edema & $5(38.4 \%)$ & $24(52.2 \%)$ & 0.278 \\
\hline Altered sensorium & $5(38.4 \%)$ & $13(28.3 \%)$ & 0.345 \\
\hline Vomiting & $4(30.7 \%)$ & $9(19.5 \%)$ & 0.567 \\
\hline $\begin{array}{l}\text { Hypertension } \\
\text { (Systolic and or } \\
\text { diastolic blood } \\
\text { pressure }>95 \text { th } \\
\text { percentile for age, } \\
\text { gender and height) }\end{array}$ & $0(\%)$ & $28(60.8 \%)$ & $<0.01$ \\
\hline $\begin{array}{l}\text { Disseminated } \\
\text { intravascular } \\
\text { coagulation }\end{array}$ & $3(23.1 \%)$ & $0(\%)$ & $<0.05$ \\
\hline $\begin{array}{l}\text { Multi-organ } \\
\text { involvements }(\geq 3)\end{array}$ & $5(38.4 \%)$ & $11(23.9 \%)$ & $<0.05$ \\
\hline
\end{tabular}

$24 \mathrm{~h}$ or anuria for $\geq 12 \mathrm{~h}$ ) or decrease in eGFRcr to $<35 \mathrm{ml} / \mathrm{min}$ per $1.73 \mathrm{~m}^{2}$ for AKI despite adequate hydration or $<15 \mathrm{ml} / \mathrm{min}$ per $1.73 \mathrm{~m}^{2}$ for CKD and with fluid overload, metabolic acidosis, electrolyte disturbances not responding to conservative treatment. Parents not giving consent and cases of kidney transplant recipients were excluded. The AKI was classified as per KDIGO clinical practice guidelines ${ }^{17}$ and $\mathrm{CKD}$ as per Kidney Disease Outcome Quality Initiative (KDOQI) guidelines. ${ }^{5}$

The detailed history, clinical features, physical examination, and investigations of each case was recorded. Haemoglobin, total and differential leucocytes count, platelet count, arterial blood gas analysis, serum urea, creatinine, sodium, potassium, calcium, phosphate, alkaline phosphatase were done in all patients at admission. Prothrombin time / international normalised ratio, HBsAg, anti-HCV, HIV screening, X-ray chest, and ultrasonography of abdomen were also done in patients with AKI and CKD. The iPTH and 25 hydroxyl vitamin $\mathrm{D}$, protein, albumin, cholesterol were estimated in children with ESRD. Serum C3, C4, ANA, anti dsDNA, cANCA, and pANCA were estimated, wherever indicated to find out etiologies.

Haemodialysis was done in the dialysis unit under the supervision of paediatric postgraduate residents
Table 2. Haematological and biochemical parameters at admission in children with AKI and CKD

\begin{tabular}{|c|c|c|c|}
\hline Investigations & $\begin{array}{l}\text { AKI stage } \\
\text { 3D } \\
(n=13)\end{array}$ & $\begin{array}{l}\text { CKD G5D } \\
(n=46)\end{array}$ & p-value \\
\hline Hemoglobin (g/dl) & $10.0 \pm 3.2$ & $7.1 \pm 2.4$ & $<0.01 *$ \\
\hline $\begin{array}{l}\text { Total leucocyte } \\
\text { counts (thousand/ } \\
\text { mm3) }\end{array}$ & $\begin{array}{l}23.032 \pm \\
8.761\end{array}$ & $\begin{array}{l}12.740 \pm \\
7.280\end{array}$ & $<0.01 *$ \\
\hline $\begin{array}{l}\text { Platelet (lakh/mm3) } \\
\text { median (IQR) }\end{array}$ & $\begin{array}{l}1.18 \\
(0.42,1.5)\end{array}$ & $\begin{array}{l}2.07 \\
(1.55,3.19)\end{array}$ & $\begin{array}{l}< \\
0.01 * *\end{array}$ \\
\hline Neutrophils (\%) & $65.3 \pm 13.6$ & $56.2 \pm 15.2$ & $0.173^{*}$ \\
\hline Lymphocyte (\%) & $31.4 \pm 12.4$ & $36.3 \pm 14.5$ & $0.313^{*}$ \\
\hline Sodium (mmol/L) & $137.0 \pm 8.9$ & $135.2 \pm 6.7$ & $0.542 *$ \\
\hline Potassium (mmol/L) & $5.2 \pm 0.6$ & $4.5 \pm 1.2$ & $0.100^{*}$ \\
\hline Calcium (mg/dL) & $7.3 \pm 3.0$ & $7.3 \pm 1.8$ & $0.900^{*}$ \\
\hline Phosphate (mg/dL) & $5.8 \pm 2.3$ & $9.0 \pm 2.9$ & $0.276^{*}$ \\
\hline $\begin{array}{l}\text { Urea }(\mathrm{mg} / \mathrm{dL}) \\
\text { median }(\mathrm{IQR})\end{array}$ & $\begin{array}{l}159.4 \\
(104.5 \\
201.5)\end{array}$ & $\begin{array}{l}198.2 \\
(152.0 \\
241.5)\end{array}$ & $0.152 * *$ \\
\hline $\begin{array}{l}\text { Creatinine (mg/dL) } \\
\text { (median (IQR) }\end{array}$ & $\begin{array}{l}5.29 \\
(2.5,7.2)\end{array}$ & $\begin{array}{l}6.8 \\
(5.3,11.6)\end{array}$ & $0.102 * *$ \\
\hline $\begin{array}{l}\text { Prothrombin time } \\
\text { (International } \\
\text { normalized ratio) }\end{array}$ & $1.4 \pm 0.29$ & $1.2 \pm 0.38$ & $0.340^{*}$ \\
\hline $\begin{array}{l}\text { Alkaline } \\
\text { phosphatase (IU/L) } \\
\text { median (IQR) }\end{array}$ & $\begin{array}{l}302 \\
(194,523)\end{array}$ & $\begin{array}{l}258 \\
(124,303)\end{array}$ & $0.316^{* *}$ \\
\hline $\begin{array}{l}\mathrm{iPTH}(\mathrm{ng} / \mathrm{l})(\mathrm{n}=31) \\
\text { median }(\mathrm{IQR})\end{array}$ & - & $\begin{array}{l}241 \\
(94,561)\end{array}$ & \\
\hline
\end{tabular}

$n$ - number of cases, IQR- interquartile range, *Student's $t$ test, ** Mann Whitney U test

and / or faculty and trained haemodialysis technician. Fresenius 4008 model haemodialysis machine was used for the purpose. Haemodialysis settings were done as per standard protocol (duration, dialyser size, volume of extracorporeal tubing, blood flow and dialyser flow rate, ultrafiltrate, and use of heparin or normal saline flush). The dialyser surface area was $0.75-1$ time of the patient's body surface area. Haemodialysis was performed using the femoral venous access. Femoral venous cannulation was carried and extracorporeal blood was returned through a $16 \mathrm{G}$ intravenous cannula placed in either median cubital vein or another side of the femoral vein. In children with haemoglobin of less than $7 \mathrm{~g} / \mathrm{dL}$, the dialysis circuit was primed with whole blood. The blood flow rate set was usually at $6-8 \mathrm{~mL} / \mathrm{kg} / \mathrm{min}$. In patients with clinical features of fluid overload and 
Table 3. Change in parameters after the first session of haemodialysis in AKI stage 3 and CKD G5D patients

\begin{tabular}{|c|c|c|c|c|c|c|c|}
\hline & \multicolumn{2}{|c|}{ AKI stage 3D $(n=13)$} & \multirow[t]{2}{*}{ p value } & \multicolumn{2}{|c|}{ CKD G5D $(n=46)$} & \multirow[t]{2}{*}{ p value } & \multirow{2}{*}{$\begin{array}{c}\text { p- value } \\
\text { AKI vs } \\
\text { CKD }\end{array}$} \\
\hline & Pre-dialysis & Post - dialysis & & Pre -dialysis & Post- dialysis & & \\
\hline Weight (kg) & $38.9 \pm 12.9$ & $38.4 \pm 12.9$ & $<0.05^{*}$ & $23.6 \pm 6.5$ & $23.2 \pm 6.4$ & $0.13^{*}$ & $0.323 *$ \\
\hline Urine output (ml/kg/hr) & $0.58 \pm 0.2$ & $0.65 \pm 0.27$ & $0.270^{*}$ & $0.9 \pm 0.5$ & $1.0 \pm 0.6$ & $0.19^{*}$ & $0.508^{*}$ \\
\hline Sodium (mmol/L) & $139.6 \pm 11.6$ & $139.3 \pm 6.3$ & $0.911^{*}$ & $135.2 \pm 8.3$ & $126.0 \pm 3.3$ & $0.187^{*}$ & $0.600^{*}$ \\
\hline Potassium (mmol/L) & $4.48 \pm 1.2$ & $4.1 \pm 0.8$ & $0.194^{*}$ & $4.6 \pm 1.2$ & $3.8 \pm 1.0$ & $<0.01^{*}$ & $0.174^{*}$ \\
\hline $\begin{array}{l}\text { Ionic Calcium (mmol/ } \\
\text { L) }\end{array}$ & $1.1 \pm 0.3$ & $1.1 \pm 0.2$ & $0.475^{*}$ & $0.82 \pm 0.2$ & $0.82 \pm 0.2$ & $0.471 *$ & $0.862 *$ \\
\hline $\begin{array}{l}\operatorname{Urea}(\mathrm{mg} / \mathrm{dL}) \\
\text { median }(\mathrm{IQR})\end{array}$ & $\begin{array}{l}188 \\
(148,212)\end{array}$ & $\begin{array}{l}139 \\
(85,175)\end{array}$ & $<0.05^{* *}$ & $\begin{array}{l}198 \\
(144,256)\end{array}$ & $\begin{array}{l}157 \\
(111,208)\end{array}$ & $<0.01 * *$ & $0.416^{* * *}$ \\
\hline $\begin{array}{l}\text { Creatinine }(\mathrm{mg} / \mathrm{dL}) \\
\text { median }(\mathrm{IQR})\end{array}$ & $\begin{array}{l}7.2 \\
(4.9,8.1)\end{array}$ & $\begin{array}{l}5.3 \\
(4.0,6.6)\end{array}$ & $<0.05^{* *}$ & $\begin{array}{l}7.5 \\
(5.5,11.2)\end{array}$ & $\begin{array}{l}5.3 \\
(3.3,9.3)\end{array}$ & $<0.001 * *$ & $0.942 * * *$ \\
\hline $\mathrm{pH}$ & $7.34 \pm 0.06$ & $7.40 \pm 0.04$ & $<0.05^{*}$ & $7.3 \pm 0.08$ & $7.38 \pm 0.08$ & $<0.001 * *$ & $0.660^{*}$ \\
\hline $\begin{array}{l}\text { Bicarbonate }(\mathrm{mmol} / \mathrm{L}) \\
\text { median }(\mathrm{IQR})\end{array}$ & $\begin{array}{l}15.6 \\
(13.5,19.9)\end{array}$ & $\begin{array}{l}20.9 \\
(15.7,24.0)\end{array}$ & $<0.05^{* *}$ & $\begin{array}{l}10.9 \\
(8.3,15.8)\end{array}$ & $\begin{array}{l}15.7 \\
(13.4,21.0)\end{array}$ & $<0.001 * *$ & $0.337 * * *$ \\
\hline $\begin{array}{l}\text { Base excess (mmol/L) } \\
\text { median (IQR) }\end{array}$ & $\begin{array}{l}-5.9 \\
(-9.4,-3.2)\end{array}$ & $\begin{array}{l}-3.4 \\
(-6.8,-3.2)\end{array}$ & $0.173 * *$ & $\begin{array}{l}-12.4 \\
(-15.9,-8.1)\end{array}$ & $\begin{array}{l}-6.5 \\
(-10.5,-3.4)\end{array}$ & $<0.001 * *$ & $<0.01 * * *$ \\
\hline
\end{tabular}

$n$ - number of cases, IQR-Interquartile range, * Student's $t$ test, **Wilcoxon signed-rank test, *** Mann-Whitney U test

pulmonary edema, ultrafiltration was $5-10 \%$ of the body weight and the patients were monitored for intradialytic hypotension. The haemodialysis settings for the first session described vide supra, were the same for both groups of patients of AKI stage 3D and CKD G5D for uniformity. All patients during dialysis were monitored every 30 minutes for vital signs such as blood pressure, heart rate, respiratory rate, oxygen saturation, and occurrence of any adverse reactions. The initial cycle of dialysis was set for $90 \mathrm{~min}$. to prevent any disequilibrium syndrome. The first assessment was done at pre-treatment at diagnosis followed by at completion of haemodialysis (immediately or some fixed time after haemodialysis). The study protocol was approved from Institute Ethics Committee. Parents of the patients included in the study were explained to participate in the study. The purpose of the study was discussed and informed consent was taken from parents (mother or father) in each case explaining the nature of the treatment, effect of haemodialysis, complications, and outcome. The data analysis was done with SPSS software version 19. Chi-square test / Fisher Exact test were used for the analysis of categorical variables. Student's t-test and Mann-Whitney U test were used to compare the data between the two groups depending upon as Gaussian and non- Gaussian distribution. Paired sample observations were tested by paired Student's t-test for Gaussian and Wilcoxon signedrank test for non - Gaussian distribution. A p-value of $<0.05$ was considered as significant.

\section{RESULTS}

Thirteen patients of AKI stage 3 (median age 12.4 years) and 46 patients of CKD G5D (median 11.4 years) in the age group of children between six to 16 years were included. There were six males $(46 \%)$ and seven females (54\%) in AKI stage 3 and $29(63 \%)$ males and 17 (37\%) females in the CKD G5D group. Etiology of AKI was sepsis in four (30.7\%), glomerulonephritis in three $(23.1 \%)$ acute tubular necrosis in two (15.4\%), diabetic ketoacidosis in two (15.4\%) and drug-induced (vancomycin) in one patient (7.6\%). In CKD group, CAKUT was the commonest cause found in 15 patients (32.6\%); among which 10 patients had posterior urethral valves, three had bilateral renal cysts, and two had urethral strictures, glomerulonephritis in seven (15.2\%), bilateral renal calculi in five $(10.8 \%)$, and one $(2.2 \%)$ case had bilateral renal artery stenosis. The exact etiology could not be known in $18(39.1 \%)$ cases. The presenting features at admission are shown in Table 1. 
Oliguria and respiratory distress were the predominant features at presentation. Hypertension and multiorgan involvements were significantly higher in CKD G5D, while disseminated intravascular coagulation was present in AKI stage 3 only. Hematological and biochemical parameters in both study groups at admission are presented in Table 2.

Mean haemoglobin was significantly lower in CKD G5D than AKI stage 3. The total leucocyte count was significantly higher and the platelet count was lower in cases of AKI stage 3D than CKD G5D. Other parameters were comparable between the two groups. Comparative analysis of change in different parameters in AKI stage 3D and CKD G5D between pre and post dialysis phase are presented in Table 3.

There were significant reduction in the median levels of serum urea, and creatinine and a rise in blood $\mathrm{pH}$, bicarbonate level, and base excess following the first session of haemodialysis in comparison to pre-dialysis values in both AKI stage 3 and CKD G5D groups. Serum potassium value showed a significant reduction in post-dialysis than the pre-dialysis period in the CKD group only. All the parameters showed similar levels of reductions in post-dialysis between AKI and CKD group, except base excess which was significantly more in CKD than AKI group. Further percent change in the levels of urea $(26 \%$ vs $20.7 \%)$, creatinine (26.4\% vs $29.3 \%)$, blood $\mathrm{pH}(0.08 \%$ vs $1.1 \%)$, bicarbonate $(33.9 \%$ vs $44 \%)$ and base excess (42.4\% vs $47.5 \%)$ were similar in both AKI stage 3 and CKD G5D, respectively. During haemodialysis, one patient developed dialysis equilibrium syndrome and two had intradialytic hypotension in the CKD G5D group. At the end of the first session, there was a reduction in weight in three patients of AKI and seven patients of CKD who had fluid overload and improvement in the level of consciousness and urine output in both groups of study subjects.

\section{DISCUSSION}

In the present study, because of the ease of vascular access in emergencies, children of six to 16 years were included for haemodialysis. The median age was relatively higher compared to other reported observations. Youssef and Neemat - Allah reported younger age (5.6 years) of the start of haemodialysis in their CKD G5 patients. ${ }^{6}$ Kamath and Iyengar found the median age of patients in children with CKD cohort to be nine years. ${ }^{7}$ The median age in our study was 11.4 years. As such CKD in our population is diagnosed late due to lack of awareness and are relatively older when they present at the referral care centre. The most common etiology of AKI was sepsis followed by acute glomerulonephritis in our study. In contrast, Mishra et al. from the same centre found haemolytic uremic syndrome as the commonest etiology (36\%) followed by sepsis $(24.6 \%)$ and acute tubular necrosis $(19.3 \%) ;{ }^{10}$ while another study reported glomerulonephritis as the most common cause $(25.3 \%)$ in the patients of AKI. ${ }^{6}$ Sepsis accounted for $30.7 \%$ of our AKI cases, therefore there was polymorphonuclear leucocytosis and some of them had disseminated intravascular coagulation also having low platelets counts. These are the haematological abnormalities at times found in patients of AKI due to sepsis at admission.

It appears that there may be geographical variation in the etiology of AKI. However, infections and glomerulonephritis were the most common etiologies of AKI in developing countries. ${ }^{3}$ CAKUT was the commonest etiology in CKD patients. The finding is similar to the other large reported registries from all over the world who reported CAKUT as the primary cause of CKD G5D. ${ }^{2}$ Hypertension was a significant co-morbidity in CKD and multi-organ involvements in AKI were significant co-morbidities at diagnosis. The patients of AKI often have multi-organ involvements. ${ }^{1,4}$ Similarly, hypertension in CKD patients is significant comorbidity and a common cause of progression and mortality in these patients. ${ }^{18,19}$

Haemoglobin was significantly lower in CKD than AKI patients. Anaemia is a common feature associated with CKD and it has been observed by other authors too. ${ }^{7,18}$ Haemodialysis was instituted in both AKI stage 3 and CKD G5D subjects and they have common indications also such as azotemia, oliguria, electrolyte abnormality, metabolic acidosis, fluid retention, and encephalopathy. The first session haemodialysis 
was performed for a shorter duration of 90 minutes. KDIGO Guidelines also emphasised the need for available renal replacement therapy in the centre for improving immediate survival in these patients. ${ }^{4}$ However, hemodiafiltration is the preferred dialytic mode in CKD patients in CKD in the developed world. It causes the removal of larger molecules like beta2 macroglobulin, better appetite, and growth. ${ }^{20}$ But non-availability of haemodiafiltration is one of the major limitations in resource-poor countries. The first session of haemodialysis lead to significant reductions in the levels of serum urea, creatinine, and base excess and rise of blood $\mathrm{pH}$ and bicarbonate in both groups of patients equally. The patients of AKI have usually a shorter duration of illness and showed rapid recovery even after the first session of haemodialysis. However, the patients of CKD needed further regular sessions of maintenance haemodialysis for correction of abnormalities, better growth, and planning kidney transplantation in the future

This is the first study that compared the efficacy of haemodialysis for renal function and clinical recovery in patients presenting with AKI stage $3 \mathrm{D}$ and CKD G5D. The main limitation of the study is that there was a lesser number of cases of AKI; limiting the generalisability of findings. However, it appears that this facility should be developed as a life-saving procedure in every tertiary care paediatric teaching centre not only for the improvement in survival of these patients but also for teaching and training to post-graduates' trainees in developing countries.

\section{CONCLUSIONS}

The study demonstrated improvement in the clinical and biochemical parameters equally after the first dialysis sessions in both groups. This is one of the effective renal replacement therapy and should be instituted wherever indicated to improve the immediate outcome of the patients.

\section{REFERENCES}

1. Krishnamurthy S, Mondal N, Narayanan P, Biswal N, Srinivasan S, Soundaravally R. Incidence and etiology of acute kidney injury in Southern India. Indian J Pediatr. 2013;80(3):183-89. DOI: 10.4103/0972-5229.118412.

2. Harambat J, Stralen KJV, Kim JJ, Tizard E J. Epidemiology of chronic kidney disease in children. Pediatr Nephrol. 2012;27:363-73. DOI: 10.1007/s00467-011-1939-1.

3. Lameire N, Biesen WV, Vanholder R. Epidemiology of ac ute kidney injury in children worldwide, including developing country. Pediatr Nephrol. 2017;32:1301-14. DOI: 10.1007/s00467-016-3433-2.

4. KDIGO clinical practice guideline for acute kidney injury: modality of renal replacement therapy for patients with AKI. Kidney Int (suppl). 2012;2:107-10. DOI:10.1038/kisup.2012.1

5. National Kidney Foundation. K/DOQI clinical practice guidelines for chronic kidney disease: evaluation, classification, and stratification. Am J Kidney Dis. 2002;39(2):S1-266. PMID: 11904577.

6. Youssef DM, Neemat-Allah MA. Hemodialysis in children: eleven years in a single center in Egypt. Iran J Kidney Dis. 2013 Nov;7(6):468-74. PMID: 24241093.

7. Asinobi AO, Ademola AD, Alao MA. Haemodialysis for paediatric acute kidney injury in a low resource setting: experience from a tertiary hospital in South West Nigeria. Clin Kidney J. 2016;9:63-8. DOI: 10.1093/ckj/sfv112.

8. Slater MB, Gruneir A, Rochon PA, Howard AW, Koren G, Parshuram CS. Risk factors of acute kidney injury in critically ill children. PediatrCrit Care Med. 2016;17:391-98. DOI: 10.1097/PCC.0000000000000859.

9. Kaddourah A, Basu R K, Bagshaw SM, Goldstein SL. Epidemiology of acute kidney injury in critically ill children and young adults. AWARE Investigators. N Engl J Med. 2017;376:11-20. DOI: 10.1056/NEJMoa1611391.

10. Mishra OP, Gupta A, Poonia V, Prasad R, Tiwary NK, Schaefer F. Peritoneal dialysis in children with acute kidney injury: A developing country experience. Perit Dial Int. 2012;32:431-36. DOI: 10.3747/pdi.2012.00118.

11. Ward BA, Chadha V. Chronic kidney disease in children: the global perspective. Pediatr Nephrol. 2007;22: 1999-2009. DOI: 10.1007/s00467-006-0410-1. 
12. Chiou YY, Lin CY, Chen MJ, Chiou YH, Wang YF, Wang HU, et al. Etiology and pediatric chronic kidney disease progression: Taiwan Pediatric Renal Collaborative Study. J Formos Med Assoc. 2016;115;752-63. DOI: 10.3390/ jcm7110414.

13. Vasudevan A, Iyengar A, Phadke K. Modality of choice for renal replacement therapy for children with acute kidney injury: Results of a survey. Indian J Nephrol. 2012;22:121-4. DOI: 10.4103/0971-4065.97130.

14. Verrina E, Edefonti A, Gianoglio B, Rinaldi S, Sorino P, Zacchello G et al., A multicenter experience on patient and technique survival in children on chronic dialysis. Pediatr Nephrol. 2004;19:82-90. DOI: 10.1007/ s00467-003-1270-6.

15. Basu B, Mahapatra TKS, Roy B, Schaefer F. Efficacy and outcomes of continuous peritoneal dialysis versus daily intermittent hemodialysis in pediatric acute kidney injury. Pediatr Nephrol. 2016;31:1681-9. DOI: 10.1007/ s00467-016-3412-7

16. Levey AS, Eckardt KU, Doman NM, Christiansen SL, Hoom EJ, Ingelfinger JR et al. Nomenclature for kidney function and disease: report of Kidney Disease: Improving Global Outcomes (KDIGO) Consensus Conference. Kidney Int. 2020;97:1117-29. DOI: DOI.org/10.1016/j.kint.2020.02.010.

17. Kidney Disease: Improving Global Outcomes (KDIGO) Acute Kidney Injury Work Group. KDIGO clinical practice guideline for acute kidney injury. Kidney Int Suppl. 2012;2:1-138. DOI:10.1038/kisup.2012.1.

18. Kamath N, Iyengar AA. Chronic kidney disease (CKD): Observational study of etiology, severity and burden of co morbidities. Indian J Pediatr. 2017;84:822-25. DOI: 10.1007/s12098-017-2413-2.

19. Wong H, Mylrea K, Feber J, Drukker A, Filler G. Prevalence of complications in children with chronic kidney disease according to KDOQI. Kidney Int. 2006;70:585-90. DOI: DOI.org/10.1038/sj.ki.5001608.

20. Shroff R, Smith C, Ranchin B, Bayazit AK, Stefanidis CJ. Effects of hemodiafiltration versus conventional hemodialysis in children with eskd : the hdf, heart and height study. J Am Soc Nephrol. 2019;30:678-91. DOI: DOI.org/10.1681/ASN. 2018100990. 